\title{
D-24 MULTIDISCIPLINARY APPROACH - A LEVERAGE FOR 3D PRE STACK DEPTH MIGRATION
}

N. PAJOLA', F. LUONI' 1 R. AWAD ${ }^{2}$ and I. EL DOSOUKI ${ }^{2}$

'Eni SpA Agip Division, Via Dell'Unione Europea 3, 20097 San Donato Milanese, Italy

\begin{abstract}
SUMMARY
The aim of the study was to obtain a reliable image of the subsurface, in order to properly evaluate the residual hydrocarbon potential of the Ras Garra Development Lease.

Target of the area is the Pre-Evaporitic (Cretaceous to Middle Miocene) sequence. The most important tectonic event that occurred in the area of interest was the opening of the Gulf of Suez during the Middle Miocene.

Owing to the structural complexity, due to the presence of an irregular salt body above the target, we followed an approach based on depth imaging methodology: the construction of a Velocity Volume and a full 3D Pre Stack Depth Migration.

In order to drive the depth imaging, several specialist studies has been performed, resulting in dipmeters, synthetic seismograms, electrofacies and magnetic profiles. This specialist studies has been integrated with a basin study. In the depth volume, two main features were indeed highlighted in the Pre-Evaporitic succession:

- a better definition of the normal faults pattern that led to easily recognize the structural highs areas;

- a good resolution of the stratigraphic sequences that allowed a satisfactory correlation with the elettrofacies, the dipmeters and the synthetic seismograms in depth.
\end{abstract}

\section{INTRODUCTION}

The Ras Garra Development Lease is located on the southern part of the Gulf of Suez, close to the Sinai coast. The minerary target is represented by pre-evaporitic sedimentary sequence. The sequence has been strongly interested by rift tectonics, witness by presence of tilted half-graben. The tilted blocks shows, in the Southern Province of Gulf of Suez, a prevailing immersion in the SW direction; this is a structure acquired during the most intense period of extension and subsidence of the rifting phase. Moreover, the salt body has been interested by an important tectonic event producing different features, such as an elongated NW-SE salt wall in the basin depocenter and a four-way salt pillow in the central part of the Lease.

The impact of the presence of sait bodies on the seismic image in Time domain is relevant: it affects the ray path, producing a deviation of the ray, reduces the penetration of the energy under the salt layer and produces a pull-up effect under the salt. This makes difficult the correct definition of the fault heaves, his position and the dip of the reflectors, increasing the uncertainty about the size and the spatial position of the prospects.

\section{DEPTH IMAGING ITERATIVE LOOP}

We followed an approach based on depth imaging: the construction of a Velocity Volume and a full 3D Pre Stack Depth Migration. The Velocity Volume was created following two main steps:

- an accurate velocity analysis;

- the definition of the geometry of the reflectors according to a consistent geological model.

The successful tools we applied to the velocity study were: 
- the choice of an horizon based approach and the definition of a vertical velocity gradient in the overburden;

- the 3D Reflection Tomography in the depth domain; velocities were updated following a global approach based on 3D ray tracing and tomographic inversion;

the 3D PreSDM TO; a 3D velocity analysis was performed at each iteration.

Once the velocities along the reflectors were defined, the velocity maps were built and were input as half space velocity to the 3D Post Stack Depth Migration iterations (3D PoSDM). The geometries of the relevant reflectors were directly defined in depth, interpreting the depth migrated volumes that were output at the end of each 3D PoSDM iteration. The whole process developed layer by layer, from the shallowest to the deepest, moving from the 3D PreSDM T.O. Velocity Study phase to the interpretation of the 3D PoSDM seismic volumes. The velocities and the geometries filled the final Velocity Volume and it was input to the full 3D PreSDM.

\section{DATA INTEGRATION}

Specialist resources have been involved during the entire workflow and the various results has been compared and integrated during the whole project. In particular, the project offered advantage of the contribution of subsurface geology department and basin geology department.

Six wells have been chosen in order to study the different geologic environment in the Lease and to cover the whole area. This specialist studies has been integrated with a structural study, in order to correctly drive the depth imaging steps, validating or discarding the intermediate results.

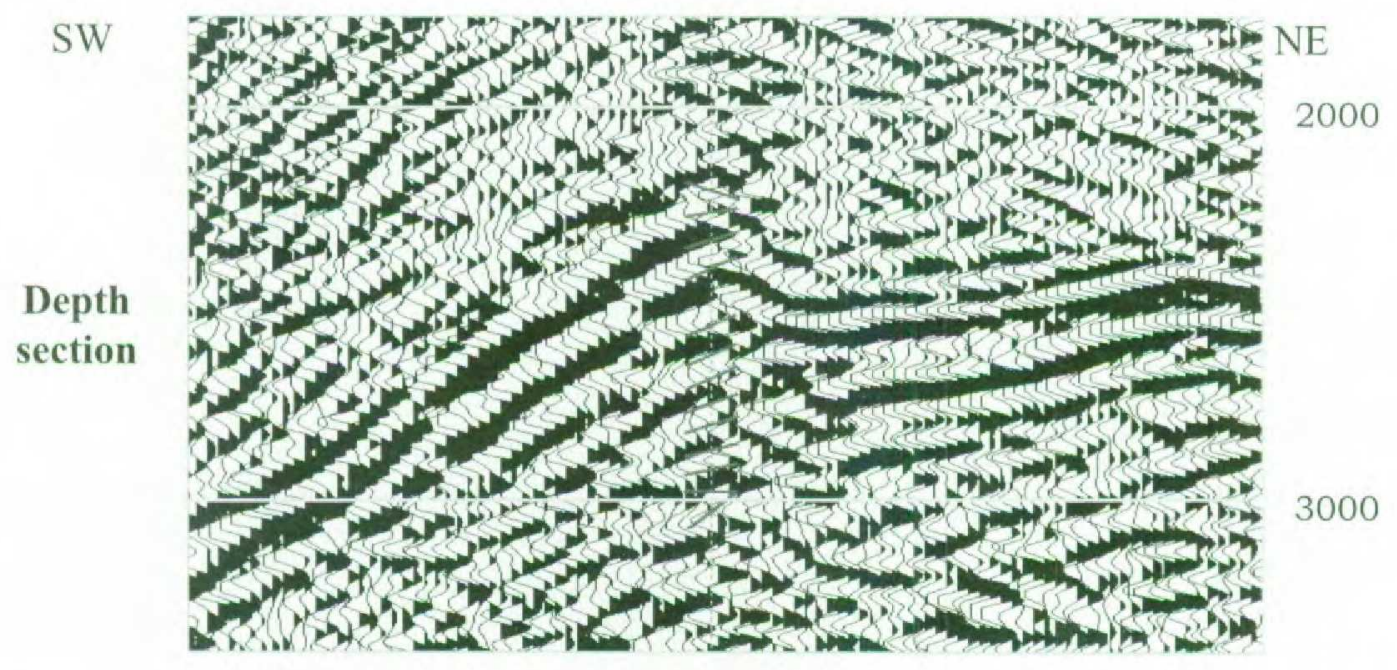

\section{Dipmeter Study}

Two objectives are achieved:

- evaluation of the regional extent of structural well data

- assessment of the quality of the processed seismic data

Two are the main steps for dipmeter to seismic integration:

- structural dipmeter interpretation and dip data reduction;

- projection of reduced dip data on selected seismic lines.

Seismic data were in the depth domain so no depth-to-time conversion has been applied to dip data. The use of this tool has been continuous during the entire depth loop, comparing the dip of the reflectors coming from the intermediate depth volumes with the dipmeters. The final depth volume shows a good agree between these two datasets.

\section{Synthetic Seismogram Study}

The synthetic seismogram processing has been done integrating the sonic log of the chosen six wells with the respective velocity. For all the wells, 3 different comparisons we produced, using 3 seismograms: 
1. Seismic Time Vs Seismogram Time

2. Seismic Depth Vs Seismogram Depth (velocity from well data)

3. Seismic depth Vs Seismogram Depth (velocity from PreSDM).

The comparison between the seismograms and the final seismic depth volume allowed both recognizing the seismic artifacts produced during the depth loop and validating the uppermost part of reflectors.

\section{Electrofacies Study}

The electrofacies study has been carried out on 8 wells. In particular, a lithofacies characterization has been performed with the following objectives:

- to characterize the pre-salt sedimentary section with particular attention to their facies and areal distribution and to compare it with the depth seismic data;

- to improve the identification of possible new targets;

- to make easier the assessment of "well to well" correlation by log and seismic interpretation;

- to extend the geological information coming from neighbor area, previously studied from biostratigraphical point of view and located in a comparable geological context.

\section{Magnetic Study}

This study has been performed in order to define the depth and the shape of the basement.

Interpreting this data, it is so possible to highlights the following points:

- The southwestern comer is characterized by the presence of a shallow magnetic basement, which crop out onshore.

- The wide elongated minimum zone characterized by a maximum depth of $5 \mathrm{Km}$ (and more) below sea level, with a NNW-SSE trend, as the East Zeit Basin.

- The wide and structurally complex high area (depth: from 3 to $4 \mathrm{Km}$ b.s.l.) of the Ras Garra Dev. Lease.

- The Ashrafi high (NNW-SSE direction) with minimum depth less than $2 \mathrm{Km}$ b.s.l..

- The generalized westward immersion characterized by the presence of a main fault with NNW-SSE direction.

\section{Structural Analysis}

The structural analysis followed the entire workflow, particularly in order to compare the produced shape of the target reflectors with the geologic model. Two main features were indeed highlighted in the PreEvaporitic succession:

- a better definition of the normal faults pattem that led to recognize more structural highs, increasing the confidence degree,

- a good resolution of the stratigraphic sequences that allowed a satisfactory correlation with the elettrofacies, the dipmeter and the synthetic seismograms in depth. The depth seismic volume helps to recognize inside the pre-salt series the presence of dominant Clismic trend and the Aqaba trend. The depth stices clearly showed the transcurrent phenomena, witness by lateral shift of major faults

\section{CONCLUSION}

The multidisciplinary approach to the Depth Imaging process allowed driving and validating the intermediate and final results. The final result was the production of depth seismic volume as well the increasing of geologic knowledge of the area, performed with the integration of specialist studies. This approach to the depth imaging, moreover, represents an effective contribution to the definition and evaluation of residual hydrocarbon potential, reducing the standard existing gap between the specialist studies and the interpretation step. The produced data (seismic data and well data) has been loaded in a project D.B., directly disposal for the interpretation step. In this way, all the data processed for depth imaging purposes has been even easily put to use during the subsequent steps of the workflow, reducing the needed time for the residual hydrocarbon potential evaluation step. Moreover, the acquired knowledge during the depth processing has been passed on to the seismic interpreters, in terms of validation and comparison between the various studies. The result has been, such an example, the possible revision of some stratigraphic tops, using electrofacies and seismic depth volume. 
The unbroken co-operation between the depth imaging team in Milan and the Petrobel geologists and geophysicists in Cairo was the key of the success, in terms of quality of the seismic depth volume and of comprehension of geologic model of the area.
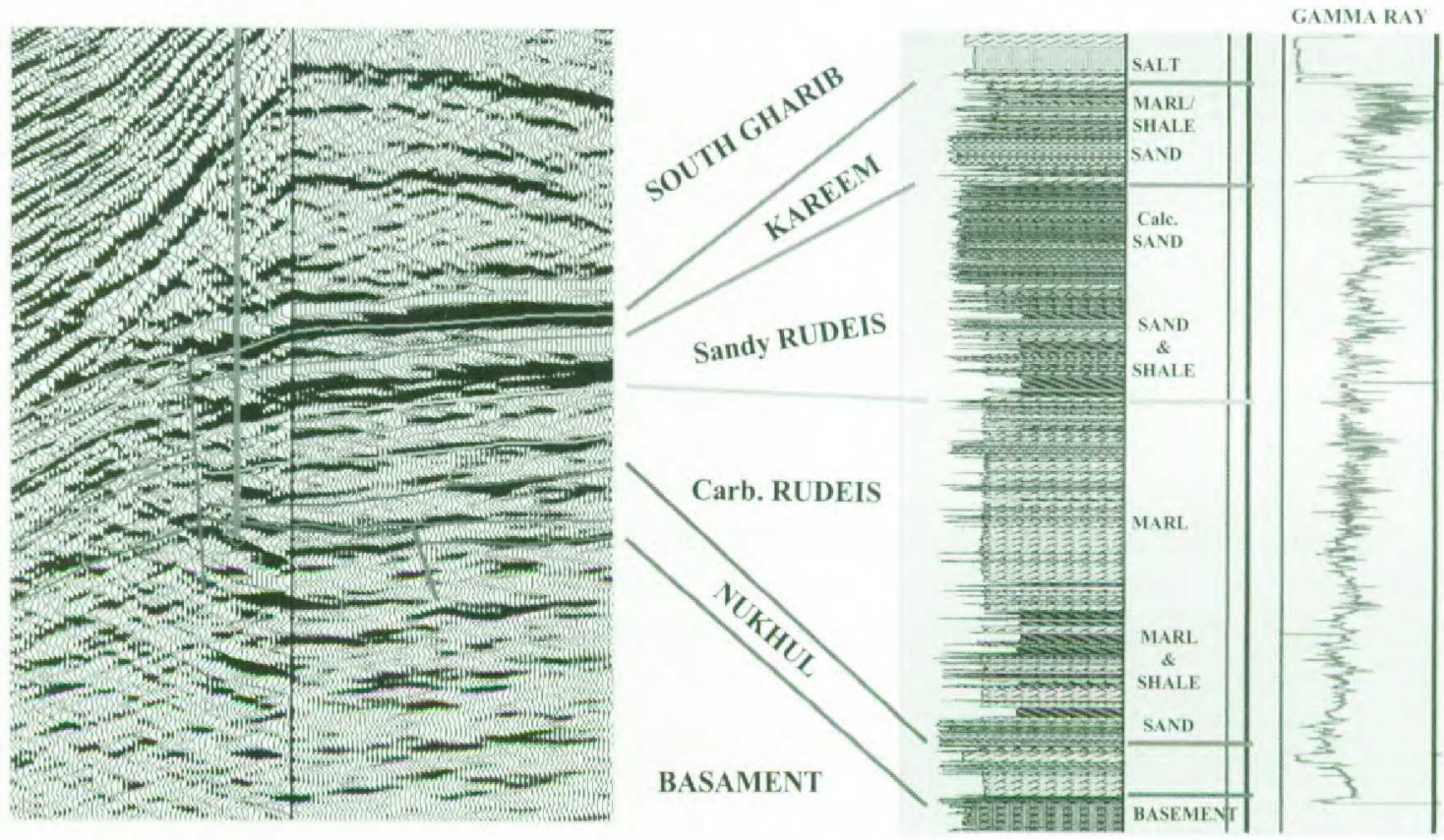

\section{ACKNOWLEDGES}

Numerous Eni Agip Div. geoscientists have contributed to the data analysis. Special thanks to P. Balossino, M. Vettorel (Subsurface Geology Dept.) and R. Longoni (Basin Geology Dept.) for their invaluable support. The authors would besides like to thank ENI-Agip Division and Belayim Petroleum Co. for their permission to publish this paper.

\section{REFERENCES}

C. Montenat, P. Ott D'Estevou, B. Purser et alii, Tectonic and sedimentary evolution of the Gulf of Suez and the northwestern Red Sea. Tectonophysics, 153 (1988) 161-177

L. Ewans, Neogene tectonic and stratigraphic events on the Gulf of Suez rift area, Egypt. Tectonophysics, 153 (1988) 235-247

N. Lyberis, Tectonic evolution of the Gulf of Suez and the Gulf of Aqaba. Tectonophysics, 153 (1988) 109-220

M. P. A. Jackson et alii, Structural dynamics of salt systems. Annual review of Earth \& Planetary Sciences, v. 22 (1994)

M. E. Mathisen, Salt structures as indicators of subsalt rift basin faults and fault-controlled reservoirs, GCSSEPM Foundation, $16^{\text {th }}$ Conf. (1995), pp. 153-170 